\title{
Preventing exercise-induced hypoglycaemia in insulin-dependent diabetes
}

\author{
Elsamma Chacko ${ }^{1}$
}

Received: 26 July 2016 / Accepted: 15 August 2016/Published online: 27 August 2016

(C) Springer-Verlag Berlin Heidelberg 2016

Keywords Hypoglycaemia · Post-meal exercise · Pre-meal exercise $\cdot$ Type 1 diabetes

To the Editor: As a practising internist on insulin for type 2 diabetes, I found the article by Thabit and Leelarathna, on exercise-induced hypoglycaemia, of much professional and personal interest [1]. In the last four years, I have personally visited the emergency department twice for severe hypoglycaemia reactions, with glucose values as low as $0.78 \mathrm{mmol} / \mathrm{l}$. One of these occurred when I did not eat for $8 \mathrm{~h}$ (14:00 to $22: 00)$ and the other was $3 \mathrm{~h}$ after a $10 \mathrm{~min}$ bout of resistance activity before my daily aerobic exercise. No doubt, exercise-induced hypoglycaemia is a constant challenge for patients on insulin. Of the options for preventing exerciseinduced hypoglycaemia listed in the article, the easiest is insulin dose reduction using an insulin pump. Continuous glucose monitoring is also helpful. Most people with type 1 diabetes, however, do not have these hi-tech options. Carbohydrate supplementation and provoking hepatic glucose output using a high energy/resistance exercise before aerobic activity may interfere with weight management and blood glucose regulation, unless the patient is extra vigilant. This letter points to a simpler exercise option for management of hyperglycaemia with minimal risk for hypoglycaemia. The key is in the timing.

In 1982 a team of Canadian scientists studied glycaemic response to moderate (55\% maximum oxygen uptake $\left.\left[\dot{V} \mathrm{O}_{2 \max }\right]\right)$ aerobic exercise in healthy people and those with

Elsamma Chacko

elsammac@msn.com

1 Connecticut Valley Hospital, 1000 Silver Street, Middletown, CT 06457, USA type 1 diabetes [2]. The exercise started $30 \mathrm{~min}$ post-breakfast and lasted for $45 \mathrm{~min}$. The activity reduced glucose levels and no hypoglycaemia ensued for the first $35 \mathrm{~min}$ of the exercise bout. When the exercise ended at $75 \mathrm{~min}$ post-meal, the glucose level slowly increased forming a small secondary peak, possibly signalling the continued arrival of exogenous glucose from the gut, offering some insurance against hypoglycaemia. Studies over the next 30 plus years have shown why the mid-postprandial period (30 min to $90 \mathrm{~min}$ post-meal) is the right time for people with diabetes to exercise $[3,4]$ : exogenous glucose is abundant in the blood, insulin:glucagon ratio is high, NEFA levels are low and hepatic glucose production is suppressed. With moderate aerobic activity, glucose transport to the muscles increases and glucose molecules fuel the physical activity, rather than contributing to the post-meal surge.

Transient hypoglycaemia may still occur if the intensity or duration of the physical activity is high [2]. Before starting an exercise regimen, it is a good idea to establish a predictable glucose profile by means of steady carbohydrate intake and medication dose. One way to coordinate meals and exercise is to designate the biggest meal of the day (preferably breakfast) as the 'exercise meal', with lunch, dinner and two to three snacks, which can be small. Eating every 2-4 h helps in guarding against hypoglycaemia. A brisk walk for $30 \mathrm{~min}$ starting $30 \mathrm{~min}$ post-breakfast would not be dangerous. Glucose should be monitored closely after exercise until the pattern in change has been determined. Here the exercise is timed to moderate the glucose surge in response to the biggest meal of the day; the other meals and associated surges are small by design.

If high intensity/resistance exercise comprises part of the exercise regimen, the risk for delayed hypoglycaemia increases [5, 6]. Frequent glucose checking and eating may become necessary. Moderate-intensity exercise during the 
pre-breakfast hours, when counterregulation acts to maintain normal blood glucose levels, may be a last-resort option for those who are prone to hypoglycaemia [7], but post-exertion hyperglycaemia may occur [3].

Short term (days) studies using continuous glucose monitoring are still needed to confirm the impact of moderate aerobic exercise during the mid-postprandial period, either alone or in combination with a short bout of high intensity/ resistance activity, on hypoglycaemia risk. Long term (months) counterparts of such studies would help determine the effects on $\mathrm{HbA}_{1 \mathrm{c}}$, lipids and markers of oxidative stress.

Funding This work received no specific funding.

Duality of interest The author declares that there is no duality of interest associated with this manuscript.

Contribution statement The author is the sole contributor to this paper.

\section{References}

1. Thabit H, Leelarathna L (2016) Basal insulin delivery reduction for exercise in type 1 diabetes: finding the sweet spot. Diabetologia 59: $1628-1631$

2. Nelson JD, Poussier P, Marliss EB, Albisser AM, Zinman B (1982) Metabolic response of normalman and insulin-infused diabetics to postprandial exercise. Am J Physiol 242:E309-E316

3. Haxhi J, di Palumbo A, Sacchetti M (2013) Exercising for metabolic control: is timing important? Ann Nutr Metab 62:14-25

4. Chacko E (2016) Exercising tactically for taming postmeal glucose surges. Scientifica. doi:10.1155/2016/4045717

5. Maran A, Pavan P, Bonsembiante B (2010) Continuous glucose monitoring reveals delayed nocturnal hypoglycaemia after intermittent high-intensity exercise in non- trained patients with type 1 diabetes. Diabetes Technol Ther 12:763-768

6. Yardley J, Mollard R, Macintosh A et al (2013) Vigorous intensity exercise for glycemic control in patients with type 1 diabetes. Can J Diabetes 7:427-432

7. Poirier P, Mawhinney S, Grondin L et al (2001) Prior meal enhances the plasma glucose lowering effect of exercise in type 2 diabetes. Med Sci Sports Exerc 33:1259-1264 